\title{
Diagnosis and treatment of coronary artery disease in hemodialysis patients evaluated for transplant
}

\author{
Jose JG De Lima ${ }^{*}$, Luis Henrique W Gowdak and Flavio J de Paula ${ }^{2}$
}

\begin{abstract}
We present a review of current strategies for the diagnosis and treatment of coronary artery disease (CAD) in patients with advanced chronic kidney disease who are on the waiting list for transplants, based on data from the literature and originated from a single-center cohort of 1,250 patients with maximum follow-up of 12 years. We discuss the best way to select patients to be tested for CAD, how to choose the more adequate screening test for CAD and cardiovascular disease, how to select patients for invasive treatment studies and how to treat patients with significant CAD. We also suggest new research avenues to be explored to resolve some problems in this area.
\end{abstract}

Keywords: Chronic kidney disease, Coronary artery disease, Renal transplantation, Myocardial scintigraphy, Coronary angiography

\section{Introduction}

Compared to the general population, patients with chronic kidney disease (CKD) are at the highest risk of developing cardiovascular complications and dying [1]. This trend has been observed in individuals with moderate reduction in renal function and increases as renal insufficiency progresses [2]. The adjusted risk of cardiovascular death for patients on dialysis is 10 to 20 times higher than that in the general population, and $50 \%$ of such deaths are related to coronary artery disease (CAD) $[3,4]$. Also, patients with CKD have a worse prognosis once one event has occurred [5], thus most patients with CKD are more likely to die as a result of cardiovascular disease (CVD) than to reach the final stages of renal failure and be started on renal replacement therapy [6]. The prevalence of significant CAD (>50\% stenosis) in dialysis patients varies between 30\% and $70 \%$ and is greatly influenced by age and the presence of diabetes as well as by the use of angiography as a diagnostic method [7-12]. Renal transplantation is associated with improved survival [13], but CVD remains the most common cause of death after transplantation [14]. Together, these facts justify the routine assessment of patients

\footnotetext{
* Correspondence: jose.lima@incor.usp.br

${ }^{1}$ Heart Institute (InCor), Hospital das Clínicas, University of São Paulo Medical

School, Rua Eneas Carvalho Aguiar, 44, 05403-000, São Paulo, Brazil

Full list of author information is available at the end of the article
}

with CKD for associated CVD and CAD, including those being considered for kidney transplantation.

The optimal way to screen for and manage CAD prior to and following kidney transplantation is a topic of intense debate in the literature. There is no firm consensus about who should be tested, which testing modality should be used and who should undergo intervention if CAD is found [15-18]. In 1997, our center started a prospective, observational study intended to determine the best clinical and cardiovascular investigations for the detection of CAD and the prediction of cardiovascular events in patients evaluated for kidney transplants. The cohort now encompasses 1,250 patients with a median follow-up of 38 months. The present article is based on the database and data collected during the follow-up periods, as well as on pertinent observations reported in the literature.

\section{Which patients should be tested for CAD?}

According to the American Society of Transplantation (AST) guidelines, the elderly, patients with diabetes and patients with associated clinical CVD (high-risk patients) should be tested for CAD [15]. High-risk patients are clinically defined by clinical evidence of actual or past vascular arterial disease, heart failure and previous stroke or myocardial infarction. Which patients should be considered at low risk is unclear, however; that is, young patients $(<50$ years old), patients without diabetes and 
those with no clinical evidence of CVD should also be tested, because CKD is considered an independent risk factor for cardiovascular death. Therefore, we tested the hypothesis that clinical stratification alone would make detailed cardiac evaluation unnecessary in low-risk patients [19]. We evaluated 363 consecutive candidates for renal transplantation followed up for 51 months. We found that only 1 of 93 low-risk patients had an adverse event (stroke), and no coronary events were observed. Contrary to that finding, 49 adverse events occurred in 270 high-risk patients, comprising 12 strokes, 12 sudden deaths, 11 cases of unstable angina, 6 myocardial infarctions, 4 congestive heart failures requiring hospitalization and 4 acute peripheral vascular events resulting in intervention. Of these adverse events, 29 (58\%) were attributed to CAD (sudden cardiac death, myocardial infarction and unstable angina). These results indicate that indepth cardiac investigation is not required in low-risk asymptomatic patients and that clinical stratification is an adequate tool to identify subjects at high risk for future cardiovascular events.

\section{What is the best screening test for CAD and cardiovascular events in high-risk patients?}

Guidelines for the detection of CAD and assessment of risk in CKD patients are based on the results of noninvasive testing, such as myocardial scanning (dipyridamole stress testing single-photon emission-computed tomography (SPECT)) and echocardiography stress testing (EST) with dobutamine-atropine on the basis of data derived from the nonuremic population [20]. In the majority of cases, the accuracy of these tests in patients with CKD was evaluated by the incidence of adverse events, with the invasive test reserved for those patients with evidence of ischemia. On the basis of using this approach, the sensibility and specificity of SPECT have been found to be highly variable by diverse authors, usually lower than $80 \%$ [21-26].

It is important to point out that epidemiological studies have indicated that a useful diagnostic test for a condition that is highly prevalent, such as CAD in CKD patients, must have sensitivity and specificity of at least $80 \%$. The negative predictive value, which incorporates the disease prevalence in its formula, should be even higher. Otherwise, a negative test is likely to represent a false-negative result.

We evaluated prospectively the accuracy of these two noninvasive tests in detecting CAD ( $\geq 70 \%$ stenosis) and assessing cardiovascular risk using coronary angiography as the "gold standard" in 126 high-risk patients classified according to the AST criteria [8]. The prevalence of CAD was $42 \%$. The sensitivity and negative predictive values of both noninvasive tests for the detection of CAD were $<75 \%$, meaning that the tests failed to identify almost onethird of patients with significant coronary stenosis. More importantly, CAD, but not the noninvasive tests, correlated with adverse events with a sensitivity of $86 \%$ and a negative predictive value of $96 \%$. The relative risk of adverse events for patients with CAD was almost 10 times higher, and CAD was the only variable significantly related to adverse events in multivariate analysis. Therefore, we concluded that the current noninvasive tests are of limited usefulness to select high-risk patients for coronary angiography and for risk stratification.

Are there alternatives to SPECT and EST? Exercise electrocardiography may be helpful but cannot be used in many CKD patients because of their low tolerance to exercise [27]. Cardiac computed tomographic angiography has not been evaluated extensively in this population, and cardiac magnetic resonance imaging is no longer indicated for patients with renal disease, owing to the risk of gadolinium-associated systemic fibrosis [28]. In our center, the accuracy of the coronary calcium score as a predictor of CAD was found to be comparable to SPECT (area under the receiver operating characteristic curve $=0.70)$ [29]. We may say that there is still no totally satisfactory screening method for CAD in this group of patients.

\section{Should all high-risk patients undergo coronary angiography?}

Because of the suboptimal performance of current noninvasive testing to detect CAD and stratify patients for cardiovascular risk, clinicians at some centers advocate the use of an invasive test for all high-risk patients. Certainly, relying only on noninvasive tests would cause $20 \%$ to $30 \%$ of high-risk patients with CAD to be undiagnosed. However, coronary angiography is expensive and not without risks. Moreover, the majority of studies have conclusively shown that the prevalence of CAD in the high-risk patients evaluated by angiography is, on average, close to $50 \%$. This means that, if we accept that approach, a significant proportion of patients will be exposed to invasive testing with no clear clinical advantage. Therefore, in our center, we are working to find ways to identify, among high-risk patients, those with a higher probability of occult significant coronary stenosis and, as a consequence, more likely to benefit from angiography.

Our hypothesis is that the levels of risk imparted by age, presence of diabetes and diverse associated CVD are not the same. For that reason, we sought to determine the clinical predictors more closely related to CAD in 301 renal transplant candidates treated by hemodialysis [30]. CAD ( $\geq 70 \%$ stenosis) was found in $45 \%$ of cases, and the clinical variables significantly associated with CAD were diabetes, peripheral vascular disease and previous myocardial infarction. More importantly, the prevalence of CAD increased with the number of clinical predictors from $26 \%$ (none) to $100 \%$ (all present), whereas the incidence of events increased two-, four- and sixfold in those with 
diabetes, vasculopathy or previous myocardial infarction, respectively $(P<0.0001)$. Using these clinical parameters to select patients for invasive testing would allow the reduction of the prevalence of unnecessary angiography from $55 \%$ (when all patients undergo angiography) to $26 \%$. However, missing the diagnosis of CAD in one-fourth of patients is still not satisfactory. Therefore, we are now seeking to refine this score by finding the precise influence of each relevant factor on prognosis. The preliminary results of this project have recently been reported [31]. In this way, we hope to find a means by which to reduce the number of invasive tests without compromising the ability to correctly identify patients with significant CAD. Meanwhile, we advocate coronary angiography for symptomatic patients, those with altered myocardial scans (either transient or fixed defects) and individuals with associated CVD, irrespective of symptoms or the results of noninvasive testing. Patients with diabetes types 1 and 2 who do not have any of the aforementioned characteristics, and regardless of how long they have had diabetes, do not undergo routine invasive evaluation.

\section{Management of coronary artery disease in patients with end-stage renal disease Clinical management}

In the current era of so-called "evidence-based medicine," the treatment of patients with CKD and concomitant CAD should be based on solid data gathered from randomized clinical trials that included a large number of patients. Despite the indisputable fact that CAD is of great importance as a major determinant of cardiovascular morbidity and mortality in patients with CKD, our knowledge of how best to treat CAD in this special group of patients is less clear by far than what we already know regarding the management of CAD in patients without CKD. The main reason is that patients with CKD are consistently more often excluded from cardiovascular trials than patients with other comorbidities, such as diabetes, hypertension or smoking. In a paper by Charytan and Kuntz, who reviewed 86 cardiovascular trials that randomized more than 400,000 patients, $80 \%$ of the trials excluded subjects with end-stage renal disease (ESRD), whereas baseline renal function was reported in only $7 \%$ of the trials [32].

The simple transposition of a proven therapeutic strategy in reducing cardiovascular morbidity and mortality in patients with CAD and preserving renal function in those with CAD and CKD may not be so simple after all. Two recent clinical trials have proven that point exactly. Since the first publication of the Scandinavian Simvastatin Survival Study in the mid-1990s, statin therapy has become one of the cornerstones of the management of patients with proven CAD (and patients at high risk for CAD) and no CKD [33]. On the other hand, in both the 4D and
AURORA studies, the use of atorvastatin or rosuvastatin, respectively, in patients at high cardiovascular risk undergoing hemodialysis failed to decrease the composite primary end point of cardiovascular death, nonfatal myocardial infarction or nonfatal stroke, even in those subgroups of patients with diabetes, a history of CVD or high levels of low-density lipoprotein (LDL) cholesterol or high-sensitivity C-reactive protein [34,35].

We must point out, however, that in both studies less than $40 \%$ of enrolled patients had any form of atherosclerotic CVD, including CAD, so those studies were not performed exclusively in patients with CAD and CKD. It is our understanding that if a patient presents with documented CAD, regardless of renal function status, statin therapy should be initiated and maintained, targeted to a level of LDL cholesterol below $70 \mathrm{mg} / \mathrm{dl}$. In fact, two post hoc studies of the 4D and AURORA data indicate that statins may reduce cardiac events in selected groups of patients treated by dialysis [36,37]. In patients with a wide range of renal insufficiency, not necessarily on dialysis, the recent SHARP trial also showed a beneficial effect of simvastatin plus ezetimibe on the incidence of major atherosclerotic events [38]. There is a clear tendency toward recommending statin therapy according to the criteria for the general population in patients with CKD. On the other hand, it is still unclear if statins should also be recommended for CKD patients with no risk factors for coronary events as defined for the general population.

In light of the lack of studies specifically conducted in patients with CKD and CAD, we recommend following the current guidelines for the overall medical management of patients with chronic CAD proposed by the American Society of Cardiology and American Heart Association or the European Society of Cardiology, which have been advocated by the National Kidney Foundation Task Force on Cardiovascular Disease since the late 1990s [39-41]. This multifaceted approach to overall cardiovascular risk reduction includes, in addition to lifestyle modifications (diet, physical activity and smoking cessation), statins and aspirin for all patients. $\beta$-blockers should be used in patients with symptomatic angina and/or after myocardial infarction as well as in patients with CAD and left ventricular dysfunction. Angiotensin-converting enzyme (ACE) inhibitors (or angiotensin type II receptor blockers (ARBs)) should be used in hypertensive patients with CAD with or without diabetes, as well as in patients with left ventricular dysfunction. Attention should be paid not only to initiating those drugs in patients with CAD and CKD on dialysis but also to keeping them on those drugs in cases of patients who undergo kidney transplantation, thereby minimizing the risk of a periprocedural cardiovascular event that could jeopardize the overall benefit conferred by an otherwise successful transplant. The possibility that renin-angiotensin blockers may cause serum creatinine levels to fall more 
slowly in recipients of live donor renal transplants still needs confirmation [42]. The dire consequences of coronary events during and in the early posttransplantation period should be always considered, however, even if some adverse side effects are anticipated.

This cardioprotective selection of drugs is increasingly being used in patients with CAD, however, for reasons that are still unclear, the prescription of these cardioprotective medications is less frequent among patients with CKD compared to the general population. In a previous study, we showed that in 119 patients with ESRD and CAD followed in a single center, the baseline use of aspirin and statins, in the range of $52 \%$ and $17 \%$, respectively, was unexpectedly low [43]. In the same study, the use of ACE inhibitors (or ARBs) in 103 patients with diabetes and CKD was only $34 \%$.

Thus, regarding the medical management of patients with CAD and stage V CKD, clinicians face two major challenges: (1) the lack of clinical trials specifically designed to assess the extension of the benefit of modern medical treatment and (2) the therapeutic nihilism that keeps physicians and healthcare providers from prescribing cardioprotective drugs with proven benefit in reducing cardiovascular mortality in the overall population.

\section{Myyocardial revascularization: percutaneous coronary intervention or coronary artery bypass graft}

The American Heart Association and American College of Cardiology recently jointly issued a document regarding criteria for the appropriateness of myocardial revascularization in patients with stable angina [44]. Briefly, myocardial revascularization procedures are indicated on the basis of three distinct elements: clinical presentation (that is, angina functional class), the results of noninvasive testing (stress-induced myocardial ischemia) and the extension of obstructive lesions. Patients who are more symptomatic and receiving optimal medical therapy with high-risk results evidenced by noninvasive tests and more extensive CAD should be referred for myocardial revascularization procedures. Again, in light of the lack of trials specifically designed to study patients with CAD and CKD, we are compelled to apply the same criteria established for patients with preserved renal function to patients with CKD.

There are two major caveats to that approach. The first one is that patients with ESRD are usually self-limited regarding physical activity, which may mask exerciseinduced ischemia as a diagnostic clue to the severity of CAD. Moreover, even when patients do present with acute coronary syndrome, fewer with renal failure will have chest pain compared to those with normal renal function, making the clinical suspicion of CAD even more challenging [45]. The second issue relates to noninvasive testing for the diagnosis of CAD in patients with
CKD. It is well-accepted now that the overall sensitivity and specificity for the diagnosis of CAD in patients with CKD are lower than those found in patients with normal renal function [46]. Therefore, clinicians may miss two of the three important elements that could lead to a clear indication for myocardial revascularization.

If one finally manages to overcome the previously alluded difficulties in the decision-making process and decides to refer a patient for a myocardial revascularization procedure, another question immediately follows: What kind of revascularization technique should be used, percutaneous or surgical?

As a general rule, the results of coronary interventions in patients with ESRD undergoing dialysis are worse than those performed in the general patient population. In various retrospective studies, perioperative death during coronary bypass graft (CABG) surgery in patients with ESRD undergoing dialysis varies from $5 \%$ to $20 \%$, roughly three to four times higher than the rate in the general patient population. The 5-year mortality in CABG patients with ESRD who are undergoing dialysis is about 48\%, compared with $15 \%$ in the general patient population [47].

Given the higher mortality rates in patients with CKD who undergo CABG surgery, referring a patient for such a risky procedure can be made only if the procedure not only provides symptom relief but also yields a clear reduction in mortality compared to those patients kept on medical treatment. In this regard, an early retrospective investigation showed that dialysis patients who underwent $C A B G$ surgery had a better prognosis than those treated medically [48]. A subsequent small, prospective study in hemodialysis patients with diabetes also showed that coronary intervention (surgery or angioplasty) was associated with reduced cardiac mortality and events [49]. It should be mentioned, however, that in both studies medical therapy was suboptimal by current standards. More recently, we looked at the impact of modern medical treatment of CAD compared to myocardial revascularization on the long-term occurrence of events in a registry of 230 patients with CKD and documented significant CAD ( $\geq 70 \%$ stenosis). In that study, 184 patients were kept on medical treatment and 46 were referred for myocardial revascularization, although 16 of them refused the procedure [50]. The event-free survival rates at 12 and 48 months were $86 \%$ and $61 \%$, respectively, for patients kept on medical treatment alone and $97 \%$ and $79 \%$, respectively, for those who had any revascularization procedure. Among those who refused the procedure, however, the event-free survival rate at 48 months was only $26 \%$. We concluded that medical therapy in selected patients promotes acceptable long-term event-free survival rates and that failure to intervene may lead to an adverse outcome when myocardial revascularization was clearly indicated on the basis of the current guidelines. 
In another study, Herzog and colleagues collected data from the US Renal Data System to compare the long-term survival of 15,784 dialysis patients after percutaneous angioplasty, coronary stenting or CABG surgery [51]. The 2-year all-cause survival rate was $56.4 \pm 1.4 \%$ (CABG surgery), $48.2 \pm 1.5 \%$ (angioplasty) and $48.4 \pm 2.0 \%$ (coronary stenting). There was a statistically significant difference between the groups that indicated superior results of surgery over the other types of treatment.

Current data support previous observations regarding the overall superior benefit of CABG surgery over percutaneous coronary intervention (PCI) with drug-eluting stents (DESs) in patients with CKD on hemodialysis. In a small, nonrandomized study, Sunagawa et al. compared the event-free survival rates in patients with CKD on hemodialysis who underwent either CABG surgery $(n=29)$ or PCI $(n=75)$ [52]. They were able to show that at 2-year follow-up, the cardiac death rate was $0 \%$ for the patients who had CABG procedures and 16\% for PCI-treated patients. During the later follow-up period, there were six deaths in the CABG group and twentyseven (including six sudden deaths) in the PCI group. These authors concluded that the use of DESs in this patient population carries a higher risk for sudden death which might be due to stent thrombosis.

As we have discussed, the currently available data gathered is based on either (1) registries of patients with CKD and significant CAD that look retrospectively at outcomes according to different therapeutic strategies or (2) post hoc analysis of subgroups of patients with CKD prospectively enrolled in cardiovascular trials. What we are in great need of is a randomized clinical trial that enrolls only patients with CKD and significant CAD in whom both strategies (medical and invasive treatments) are equally justifiable based on current guidelines. Such a study has been proposed [53] and would provide the best evidence for choosing the right therapeutic strategy for treating CAD in this high-risk group of patients.

\section{Conclusion}

CAD is a common and important complication in patients with advanced CKD. Because patients with CKD are frequently excluded from cardiovascular trials, no clear strategies have been developed specifically for the detection and treatment of CAD in these patients. That is one of the reasons for the erratic and disappointing results reported in the diagnosis and treatment of CAD in this population. Clinicians are in great need of randomized clinical trials that enroll solely patients with CKD in whom diagnostic and treatment strategies are tested based on current guidelines. Such studies would provide the best evidence for choosing the right strategy to screen and treat $\mathrm{CAD}$ in this high-risk group of patients.

\section{Competing interests}

The authors declare that they have no competing interest.

\section{Acknowledgements}

This work was supported by grants from the Zerbini Foundation and Fundação de Amparo à Pesquisa do Estado de São Paulo (FAPESP), São Paulo, Brazil.

\section{Author details}

${ }^{1}$ Heart Institute (InCor), Hospital das Clínicas, University of São Paulo Medical School, Rua Eneas Carvalho Aguiar, 44, 05403-000, São Paulo, Brazil. ${ }^{2}$ Renal Transplant Unit, Urology, Hospital das Clínicas, University of São Paulo Medical School, Rua Eneas Carvalho Aguiar, 39, 05403-000 São Paulo, Brazil.

\section{Authors' contributions}

JJGL, LHWG and FJP conceived the work and wrote the manuscript. All authors read and approved the final manuscript.

Received: 6 October 2011 Accepted: 24 April 2012

Published: 24 April 2012

\section{References}

1. Sarnak MJ, Levey AS, Schoolverth AC, Coresh J, Culleton B, Hamm LL, McCullough PA, Kasiske BL, Kelepouris E, Klag MJ, Parfrey P, Pfeffer M, Raij L, Spinosa DJ, Wilson PW, American Heart Association Councils on Kidney in Cardiovascular Disease, High Blood Pressure Research, Clinical Cardiology, and Epidemiology and Prevention: Kidney disease as a risk factor for development of cardiovascular disease: a statement from the American Heart Association Councils on Kidney in Cardiovascular, High Blood Pressure Research, Clinical Cardiology, and Epidemiology and Prevention. Circulation 2003, 108:2154-2169.

2. Go AS, Chertow GM, Fan D, McCulloch CE, Hsu CY: Chronic kidney disease and the risks of death, cardiovascular events, and hospitalization. $N$ Engl J Med 2004, 351:1296-1305.

3. United States Renal Data System: USRDS 2005 Annual Data Report: Atlas of End-Stage Renal Disease in the United States. Bethesda, MD: National Institutes of Health, National Institute of Diabetes and Digestive and Kidney Diseases; 2005. [http://www.usrds.org/atlas05.aspx]

4. Foley RN, Parfrey PS, Sarnak MJ: Clinical epidemiology of cardiovascular disease in chronic renal disease. Am J Kidney Dis 1998, 32(5 Suppl 3):S112-S119.

5. Wright RS, Reeder GS, Herzog CA, Albright RC, Williams BA, Dvorak DL, Miller WL, Murphy JG, Kopecky SL, Jaffe AS: Acute myocardial infarction and renal dysfunction: a high-risk combination. Ann Intern Med 2002, 137:563-570.

6. Coresh J, Astor BC, Greene T, Eknoyan G, Levey AS: Prevalence of chronic kidney disease and decreased kidney function in the US adult population: Third National Health and Nutrition Examination Survey. Am J Kidney Dis 2003, 41:1-12.

7. Rostand SG, Kirk KA, Rutsky EA: Dialysis-associated ischemic heart disease: insights from coronary angiography. Kidney Int 1984, 25:653-659.

8. De Lima JJ, Sabbaga E, Vieira ML, de Paula FJ, lanhez LE, Krieger EM, Ramires JA: Coronary angiography is the best predictor of events in renal transplant candidates compared with noninvasive testing. Hypertension 2003, 42:263-268.

9. Fishbane S: Cardiovascular risk evaluation before transplantation. J Am Soc Nephrol 2005, 16:843-845.

10. Ohtake T, Kobayashi S, Moriya H, Negishi K, Okamoto K, Maesato K, Saito S: High prevalence of occult coronary artery stenosis in patients with chronic kidney disease at the initiation of renal replacement therapy: an angiographic examination. J Am Soc Nephrol 2005, 16:1141-1148.

11. Goldsmith DJ, Covic A: Coronary artery disease in uremia: etiology, diagnosis, and therapy. Kidney Int 2001, 60:2059-2078.

12. Gowdak LHW, de Paula FJ, César LA, Filho EE, lanhez LE, Krieger EM, Ramires JA, De Lima JJG: Diabetes and coronary artery disease impose similar cardiovascular morbidity and mortality on renal transplant candidates. Nephrol Dial Transplant 2007, 22:1456-1461.

13. Wolfe RA, Ashby VB, Milford EL, Ojo AO, Ettenger RE, Agodoa LY, Held PJ, Port FK: Comparison of mortality in all patients on dialysis, patients on dialysis awaiting transplantation, and recipients of a first cadaveric transplant. N Engl J Med 1999, 341:1725-1730. 
14. Ojo AO, Hanson JA, Wolfe RA, Leichtman AB, Agodoa LY, Port FK: Long-term survival in renal transplant recipients with graft function. Kidney Int 2000, 57:307-313.

15. Kasiske BL, Cangro CB, Hricik DE Hariharan S, Kerman RH, Roth D, Rush DN, Vazquez MA, Weir MR, American Society of Transplantation: The evaluation of renal transplant candidates: clinical practice guidelines. Am J Transplant 2001, 2(1 Suppl 2):3-95.

16. Saw J, Levin A, Gin K: Coronary artery disease in chronic kidney disease patients: assessing the evidence for diagnosis, screening and revascularization. Can J Cardiol 2004, 20:807-813.

17. Gill JS, Ma I, Landsberg D, Johnson N, Levin A: Cardiovascular events and investigation in patients who are awaiting cadaveric kidney transplant. Am Soc Nephrol 2005, 16:808-816.

18. Pilmore $\mathrm{H}$ : Cardiac assessment for renal transplantation. Am J Transplant 2006, 6:659-665.

19. Arantes RL, Gowdak LH, de Paula FJ, lanhez LE, Ramires JA, Krieger EM, De Lima JJ: Myocardial scintigraphy and clinical stratification as predictors of events in renal transplant candidates. J Nephrol 2010, 23:314-320.

20. Fleisher LA, Beckman JA, Brown KA, Calkins H, Chaikof E, Fleischmann KE, Freeman WK, Froehlich JB, Kasper EK, Kersten JR, Riegel B, Robb JF; ACC/ AHA Task Force Members, Smith SC Jr, Jacobs AK, Adams CD, Anderson JL, Antman EM, Buller CE, Creager MA, Ettinger SM, Faxon DP, Fuster V, Halperin JL, Hiratzka LF, Hunt SA, Lytle BW, Ornato JP, Page RL, Riegel B, Tarkington LG, Yancy CW: ACC/AHA 2007 Guidelines on Perioperative Cardiovascular Evaluation and Care for Noncardiac Surgery. Executive summary: A Report of the American College of Cardiology/American Heart Association Task Force on Practice Guidelines (Writing Committee to Revise the 2002 Guidelines on Perioperative Cardiovascular Evaluation for Noncardiac Surgery): Developed in Collaboration With the American Society of Echocardiography, American Society of Nuclear Cardiology, Heart Rhythm Society, Society of Cardiovascular Anesthesiologists, Society for Cardiovascular Angiography and Interventions, Society for Vascular Medicine and Biology, and Society for Vascular Surgery. Circulation 2007, 116:1971-1996.

21. Rabbat CG, Treleaven DJ, Russell JD, Ludwin D, Cook DJ: Prognostic value of myocardial perfusion studies in patients with end-stage renal disease assessed for kidney or kidney-pancreas transplant: a meta-analysis. J Am Soc Nephrol 2003, 14:431-439.

22. Le A, Wilson R, Douek K, Pulliam L, Tolzman D, Norman D, Barry J, Bennett W: Prospective risk stratification in renal transplant candidates for cardiac death. Am J Kidney Dis 1994, 24:65-71.

23. Marwick TH, Steinmuller DR, Underwood DA, Hobbs RE, Go RT, Swift C, Braun WE: Ineffectiveness of dipyridamole SPECT thallium imaging as a screening technique for coronary artery disease in patients with endstage renal failure. Transplantation 1990, 49:100-103.

24. Holley $J$, Fenton RA, Arthur RS: Thallium stress testing does not predict cardiovascular risk in diabetic patients with end-stage renal disease undergoing cadaveric renal transplantation. Am J Med 1991, 90:563-570

25. Dahan $M$, Viron BM, Faraggi $M$, Himbert DL, Lagallicier BJ, Kolta AM, Pessione F, Le Guludec D, Gourgon R, Mignon FE: Diagnostic accuracy and prognostic value of combined dipyridamole-exercise thallium imaging in hemodialysis patients. Kidney Int 1998, 54:255-262.

26. Brown JH, Vites NP, Testa HJ, Prescott MC, Hunt LP, Gokal R, Mallick NP. Value of thallium myocardium imaging in the prediction of future cardiovascular events in patients with end-stage renal failure. Nephrol Dial Transplant 1993, 8:433-437.

27. Patel RK, Mark PB, Johnston N, McGeoch R, Lindsay M, Kingsmore DB, Dargie $\mathrm{HJ}$, Jardine AG: Prognostic value of cardiovascular screening in potential renal transplant recipients: a single-center prospective observational study. Am J Transplant 2008, 8:1673-1683.

28. Perazella MA: Nephrogenic systemic fibrosis, kidney disease, and gadolinium: is there a link? Clin J Am Soc Nephrol 2007, 2:200-202.

29. Rosário MA, Lima JJ, Parga JR Avila LF, Gowdak LH, Lemos PA, Rochitte CE: [Coronary calcium score as predictor of stenosis and events in pretransplant renal chronic failure] [in English, Portuguese, Spanish]. Arg Bras Cardiol 2010, 94:236-243, 252-260, 239-247.

30. Gowdak LH, de Paula FJ, César LA, Martinez Filho EE, lanhez LE, Krieger EM, Ramires JA, De Lima JJ: Screening for significant coronary artery disease in high-risk renal transplant candidates. Coron Artery Dis 2007, 18:553-558

31. Gowdak LH, de Paula FJ, Arantes RL Kriger EM, Ramires JAF, De Lima JJ: A new risk-score model to predict the presence of significant coronary artery disease in renal transplant candidates [abstract]. Eur Heart J 2010, 31(Suppl 1):2141.

32. Charytan D, Kuntz RE: The exclusion of patients with chronic kidney disease from clinical trials in coronary artery disease. Kidney Int 2006, 70:2021-2030.

33. Randomised trial of cholesterol lowering in 4444 patients with coronary heart disease: the Scandinavian Simvastatin Survival Study (4 S). Lancet 1994, 344:1383-1389.

34. Wanner C, Krane V, März W, Olschewski M, Mann JF, Ruf G, Ritz E, German Diabetes and Dialysis Study Investigators: Atorvastatin in patients with type 2 diabetes mellitus undergoing hemodialysis. N Engl J Med 2005, 353:238-248. A published erratum appears in. N Engl J Med 2005, 353:1640.

35. Fellström BC, Jardine AG, Schmieder RE, Holdaas $H$, Bannister $K$, Beutler J, Chae DW, Chevaile A, Cobbe SM, Grönhagen-Riska C, De Lima JJ, Lins R, Mayer G, McMahon AW, Parving HH, Remuzzi G, Samuelsson O, Sonkodi S, Sci D, Süleymanlar G, Tsakiris D, Tesar V, Todorov V, Wiecek A, Wüthrich RP, Gottlow M, Johnsson E, Zannad F, AURORA Study Group: Rosuvastatin and cardiovascular events in patients undergoing hemodialysis. N Engl J Med 2009, 360:1395-1407.

36. März W, Genser B, Drechsler C, Krane V, Grammer TB, Ritz E, Stojakovic T, Scharnagl H, Winkler K, Holme I, Holdaas H, Wanner C: German Diabetes and Dialysis Study Investigators: Atorvastatin and low-density lipoprotein cholesterol in type 2 diabetes mellitus patients on hemodialysis. Clin J Am Soc Nephrol 2011, 6:1316-1325.

37. Holdaas H, Holme I, Schmieder RE, Jardine AG, Zannad F, Norby GE, Fellström BC, AURORA Study Group: Rosuvastatin in diabetic hemodialysis patients. J Am Soc Nephrol 2011, 22:1335-1341.

38. Baigent C, Landray MJ, Reith C, Emberson J, Wheeler DC, Tomson C, Wanner C, Krane V, Cass A, Craig J, Neal B, Jiang L, Hooi LS, Levin A, Agodoa L, Gaziano M, Kasiske B, Walker R, Massy ZA, Feldt-Rasmussen B, Krairittichai U, Ophascharoensuk V, Fellström B, Holdaas H, Tesar V, Wiecek A, Grobbee D, de Zeeuw D, Grönhagen-Riska C, Dasgupta T, Lewis D, Herrington W, Mafham M, Majoni W, Wallendszus K, Grimm R, Pedersen T, Tobert J, Armitage J, Baxter A, Bray C, Chen Y, Chen Z, Hill M, Knott C, Parish S, Simpson D, Sleight P, Young A, Collins R, SHARP Investigators: The effects of lowering LDL cholesterol with simvastatin plus ezetimibe in patients with chronic kidney disease (Study of Heart and Renal Protection): a randomised placebo-controlled trial. Lancet 2011, 377:2181-2192.

39. Fraker TD Jr, Fihn SD, Gibbons RJ, Abrams J, Chatterjee K, Daley J, Deedwania PC, Douglas JS, Ferguson TB Jr, Fihn SD, Gardin JM, O'Rourke RA, Williams SV, Smith SC Jr, Jacobs AK, Adams CD, Anderson JL, Buller CE, Creager MA, Ettinger SM, Halperin JL, Hunt SA, Krumholz HM, Kushner FG, Lytle BW, Nishimura R, Page RL, Riegel B, Tarkington LG, Yancy CW; American College of Cardiology; American Heart Association; American College of Cardiology/American Heart Association Task Force on Practice Guidelines Writing Group: 2007 chronic angina focused update of the ACC/AHA 2002 guidelines for the management of patients chronic stable angina: a report of the American College of Cardiology/American Heart Association Task Force on Practice Guidelines Writing Group to Develop the Focused Update of the 2002 guidelines for the management of patients with chronic stable angina. Circulation 2007, 116:2762-2772. A published erratum appears in Circulation 2007, 116:e558

40. Fox K, Garcia MA, Ardissino D, Buszman P, Camici PG, Crea F, Daly C, De Backer G, Hjemdahl P, Lopez-Sendon J, Marco J, Morais J, Pepper J, Sechtem U, Simoons M, Thygesen K, Priori SG, Blanc JJ, Budaj A, Camm J, Dean V, Deckers J, Dickstein K, Lekakis J, McGregor K, Metra M, Morais J, Osterspey A, Tamargo J, Zamorano JL: Task Force on the Management of Stable Angina Pectoris of the European Society of Cardiology; ESC Committee for Practice Guidelines (CPG): Guidelines on the management of stable angina pectoris: executive summary. The Task Force on the Management of Stable Angina Pectoris of the European Society of Cardiology. Eur Heart J 2006, 27:1341-1381.

41. Levey AS, Beto JA, Coronado BE, Eknoyan G, Foley RN, Kasiske BL, Klag MJ, Mailloux LU, Manske CL, Meyer KB, Parfrey PS, Pfeffer MA, Wenger NK, Wilson PW, Wright JT Jr: Controlling the epidemic of cardiovascular 
disease in chronic renal disease: What do we know? What do we need to learn? Where do we go from here? National Kidney Foundation Task Force on Cardiovascular Disease. Am J Kidney Dis 1998, 32:853-906.

42. Stevens KK, Patel RK, Clancy M, Jardine AG: Angiotensin blockade is associated with early graft dysfunction after live donor renal transplantation. Transplantation 2010, 89:707-709.

43. Gowdak LHW, Arantes RL, de Paula FJ, Krieger EM, De Lima JJG: Underuse of American College of Cardiology/American Heart Association Guidelines in hemodialysis patients. Ren Fail 2007, 29:559-565.

44. Patel MR, Dehmer GJ, Hirshfeld JW, Smith PK, Spertus JA: American College of Cardiology Foundation Appropriateness Criteria Task Force; Society for Cardiovascular Angiography and Interventions; Society of Thoracic Surgeons; American Association for Thoracic Surgery; American Heart Association, and the American Society of Nuclear Cardiology Endorsed by the American Society of Echocardiography; Heart Failure Society of America; Society of Cardiovascular Computed Tomography: ACCF/SCAI/ STS/AATS/AHA/ASNC 2009 Appropriateness Criteria for Coronary Revascularization: a report by the American College of Cardiology Foundation Appropriateness Criteria Task Force, Society for Cardiovascular Angiography and Interventions, Society of Thoracic Surgeons, American Association for Thoracic Surgery, American Heart Association, and the American Society of Nuclear Cardiology Endorsed by the American Society of Echocardiography, the Heart Failure Society of America, and the Society of Cardiovascular Computed Tomography. Am Coll Cardiol 2009, 53:530-553.

45. Szummer K, Lundman P, Jacobson SH, Schön S, Lindbäck J, Stenestrand U, Wallentin $L$, Jernberg $T$, SWEDEHEART: Relation between renal function, presentation, use of therapies and in-hospital complications in acute coronary syndrome: data from the SWEDEHEART register. J Intern Med 2010, 268:40-49.

46. Andrade JM, Gowdak LHW, Giorgi MC, de Paula FJ, Kalil-Filho R, De Lima $J \mathrm{JG}$, Rochitte CE: Cardiac MRI for detection of unrecognized myocardial infarction in patients with end-stage renal disease: comparison with ECG and scintigraphy. AJR Am J Roentgenol 2009, 193:W25-W32.

47. Gupta R, Birnbaum Y, Uretsky BF: The renal patient with coronary artery disease: current concepts and dilemmas. J Am Coll Cardiol 2004, 44:1343-1353.

48. Opsahl JA, Husebye DG, Helseth HK, Collins AJ: Coronary artery bypass surgery in patients on maintenance dialysis: long-term survival. Am J Kidney Dis 1988, 12:271-274.

49. Manske CL, Wang Y, Rector T, Wilson RF, White CW: Coronary revascularisation in insulin-dependent diabetic patients with chronic renal failure. Lancet 1992, 340:998-1002.

50. De Lima JJG, Gowdak LHW, de Paula FJ, Arantes RL, de Oliveira AL, Ramires $J A$, César LA, Krieger EM: Treatment of coronary artery disease in hemodialysis patients evaluated for transplant: a registry study. Transplantation 2010, 89:845-850.

51. Herzog CA, Ma JZ, Collins AJ: Comparative survival of dialysis patients in the United States after coronary angioplasty, coronary artery stenting, and coronary artery bypass surgery and impact of diabetes. Circulation 2002, 106:2207-2211.

52. Sunagawa G, Komiya T, Tamura N, Sakaguchi G, Kobayashi T, Murashita T: Coronary artery bypass surgery is superior to percutaneous coronary intervention with drug-eluting stents for patients with chronic renal failure on hemodialysis. Ann Thorac Surg 2010, 89:1896-1900.

53. Kasiske BL, Israni AK, Snyder JJ, Camarena A: Design considerations and feasibility for a clinical trial to examine coronary screening before kidney transplantation. Am J Kidney Dis 2011, 67:908-916.

doi:10.1186/2047-1440-1-3

Cite this article as: Lima et al: Diagnosis and treatment of coronary artery disease in hemodialysis patients evaluated for transplant. Transplantation Research 2012 1:3.

\section{Submit your next manuscript to BioMed Central and take full advantage of:}

- Convenient online submission

- Thorough peer review

- No space constraints or color figure charges

- Immediate publication on acceptance

- Inclusion in PubMed, CAS, Scopus and Google Scholar

- Research which is freely available for redistribution

Submit your manuscript at www.biomedcentral.com/submit
() Biomed Central 